\title{
Effect of Lipopolysaccharide-Induced Immune Responses on Pregnancy Loss in Ewes
}

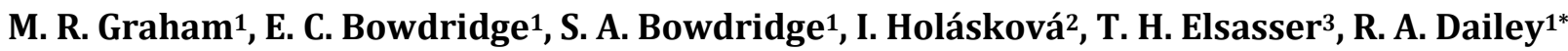 \\ ${ }^{1}$ Division of Animal and Nutritional Sciences, West Virginia University, Morgantown, USA \\ ${ }^{2}$ Office of Statistics, Davis College of Agriculture, Natural Resources and Design, West Virginia University, \\ Morgantown, USA \\ ${ }^{3}$ Animal Bioscience and Biotechnology Laboratory, USDA-ARS, Beltsville, USA \\ Email: *rdailey@wvu.edu
}

How to cite this paper: Graham, M.R., Bowdridge, E.C., Bowdridge, S.A., Holásková, I., Elsasser, T.H. and Dailey, R.A. (2018) Effect of Lipopolysaccharide-Induced Immune Responses on Pregnancy Loss in Ewese. Open Journal of Animal Sciences, 8, 421-431.

https://doi.org/10.4236/ojas.2018.84031

Received: September 21, 2018

Accepted: October 19, 2018

Published: October 22, 2018

Copyright $\odot 2018$ by authors and Scientific Research Publishing Inc. This work is licensed under the Creative Commons Attribution International License (CC BY 4.0).

http://creativecommons.org/licenses/by/4.0/ (c) (i) Open Access

\begin{abstract}
An acute phase response induced by Gram-negative bacteria can reduce pregnancy rate. Early pregnant ewes were used to monitor effects of lipopolysaccharide (LPS), an endotoxin in the outer cell membrane of Gram-negative bacteria, on acute phase/innate immunity response. In Exp. 1, mixed breed ewes were assigned to receive either LPS or LPS and flunixin meglumine, an inhibitor of prostaglandin synthetase, intravenously on day 5 after mating. In Exp. 2, mixed breed ewes were assigned to receive an intravenous injection on day 5 after mating of either saline, LPS, recombinant human tumor necrosis factor (TNF)- $\alpha$ or LPS after pretreatment with dexamethasone. Pregnancy was diagnosed ultrasonographically on $\mathrm{d} 25$, and live births were recorded at parturition. Challenge with LPS induced acute phase responses (fever, mucosal responses, lethargy and increased serum TNF, haptoglobin and serum amyloid A) and decreased pregnancy rates. Predictably, flunixin meglumine attenuated fever but did not increase pregnancy rate in LPS-treated ewes. Similarly, exogenous TNF alone induced mucosal and serum amyloid A responses but did not affect pregnancy. Pre-treatment with dexamethasone blocked fever and mucosal and lethargic responses and attenuated increases in TNF and haptoglobin but did not ameliorate LPS-induced pregnancy loss. In summary, acute challenge with LPS mimics bacterial-induced pregnancy losses in early pregnant ewes. Although pretreatment with dexamethasone decreased clinical signs and some innate immune responses, neither it nor flunixin meglumine prevented LPS-induced pregnancy loss. That exogenous TNF alone did not promote pregnancy loss indicates that other cytokines also contribute to LPS-induced embryonic loss.
\end{abstract}

\section{Keywords}

Acute Phase Response, Pregnancy Loss, Sheep 


\section{Introduction}

Infectious disease can reduce pregnancy rate. For example, conception rate in cattle decreased if mastitis occurred before first insemination, and more inseminations were required to establish pregnancy if cows were infected in early as opposed to later pregnancy [1]. The early immune response associated with bacterial challenges likely compromises establishment or early maintenance of pregnancy [2] [3].

Both lipopolysaccharide (LPS), a component of Gram-negative bacteria, and peptidoglycan-polysaccharide, a component of Gram-positive bacteria, have been used to investigate the mechanism by which bacterial infection leads to early embryonic failure. LPS induced luteolysis and reduced conception rate and early embryonic survival through release of inflammatory mediators [4]. Although LPS alone reduced embryonic development of cultured mouse embryos in one study [5], LPS reduced development only if mouse embryos also were exposed to TNF in another study [6]. Ewes inoculated with either peptidoglycan-polysaccharide [7] or a heat-killed Gram-positive bacterium, Streptococcus pyogenes, [8] on day 5 after mating had increased early embryonic losses. Injection of peptidoglycan-polysaccharide on day 5 after mating resulted in acute phase response [APR: fever and increased jugular plasma concentrations of TNF, haptoglobin (Hp) and serum amyloid A (SAA)], decreased concentrations of progesterone on days 14 and 21 and interfered with establishment of early pregnancy [9].

Two other molecules produced during inflammation, prostaglandin (PG) F2 $\alpha$ and cortisol [7] might compromise embryo survival. In several tissues, including the endometrium, LPS, inflammatory cytokines such as TNF and interleukin- $1 \beta$ (IL-1 $\beta$ ), and glucocorticoids increased synthesis of PGF2 $\alpha$ [10]. Therefore, the present studies were conducted to characterize components of the mechanism through which LPS affects reproductive efficiency in early pregnant ewes and to determine if treatment with anti-inflammatory drugs, specifically flunixin meglumine, an inhibitor of prostaglandin synthetase, or dexamethasone, a synthetic corticoid, alters the LPS-induced acute phase response.

\section{Materials and Methods}

\subsection{Animals and Experimental Designs}

Two experiments were conducted under an approved institutional animal care and use protocol of West Virginia University (IACUC \#13-0404). Mixed breed multiparous ewes were group housed and fed native grass hay with ad libitum access to water. Ewes were synchronized for estrus (Exp. 1 [11] Exp. 2 [12]) and observed every $12 \mathrm{~h}$ for signs of mating (day 0 ) while housed with fertile rams, each fitted with a marking harness. On day 4 a catheter was inserted into a jugular vein. Eighteen ewes ( 2 - 4 years of age and $\sim 80 \mathrm{~kg} \mathrm{BW}$ ) in Exp. 1 were assigned randomly ( $\mathrm{n}=9 /$ group) on day 5 to receive via a jugular vein either 2.5 $\mu \mathrm{g} / \mathrm{kg}$ LPS (E. coli O55: B5, Sigma Aldrich, St. Louis, MO) or $2.5 \mu \mathrm{g} / \mathrm{kg}$ LPS and 
$2.2 \mathrm{mg} / \mathrm{kg}$ BW flunixin meglumine (Merck Animal Health Madison NJ) at -6 and $0 \mathrm{~h}$ to test whether an inhibitor of prostaglandin synthetase would alter the induced immunologic response. This dose of LPS has been used in previous experiments [13] [14], and the dosage of flunixin meglumine is the recommended veterinary dosage for sheep (Merck Animal Health Madison NJ). In Exp. 2, 38 ewes ( $\sim 50 \mathrm{~kg} \mathrm{BW})$ were assigned randomly to receive on day 5 via a jugular vein either $2.5 \mathrm{~mL}$ saline $(\mathrm{n}=10), 2.5 \mathrm{~mL}$ of $2.5 \mu \mathrm{g} / \mathrm{kg}$ of LPS $(\mathrm{n}=9), 5 \mathrm{~mL}$ of $1 \mu \mathrm{g} / \mathrm{kg}$ of recombinant human TNF ( $n=9$, PeproTech, Rocky Hill, NJ) in two bolus injections given $30 \mathrm{~min}$ apart, or $2.5 \mathrm{~mL}$ of $2.5 \mu \mathrm{g} / \mathrm{kg}$ of LPS and $3.5 \mathrm{~mL}$ of $0.14 \mathrm{mg} / \mathrm{kg}$ BW dexamethasone ( $\mathrm{n}=10$, Dexasone Sparhawk Laboratories, Inc., Lenexa, KS) at 12 hours before and at the time of injection of LPS ( $0 \mathrm{~h})$ to test whether exogenous TNF alone would alter pregnancy status and if exogenous corticoid could alter the LPS-induced responses.

\subsection{Blood Sampling and Physical Measures}

Jugular samples were collected into EDTA-treated tubes (World Wide Life Sciences Division, Inc., Bristol, PA) prior to and every 15-min for $6 \mathrm{~h}$ (Exp. 1) or every 30-min for $3 \mathrm{~h}$ (Exp. 2), hourly for $12 \mathrm{~h}$, and then daily (Exp. 1) or twice daily (Exp. 2) through day 7. Plasma was stored at $-80^{\circ} \mathrm{C}$. Changes in rectal temperatures (Exp. 1 and 2) and behaviors and/or physical appearances (Exp. 2) were recorded during the first $12 \mathrm{~h}$ of blood sampling. Trans-rectal ultrasonography (7.5 MHz transducer and Aloka 500 ultrasound console, Corometrics Medical Systems, Inc., Wallingford CT) on day 25 was used to verify pregnancy via visualization of an embryonic heartbeat. Lambing response was recorded in Exp. 2.

\subsection{Assays}

Concentrations of TNF were assayed by RIA [15], an assay used previously [9] to measure TNF in sheep plasma, in duplicate in a single assay with an intra-assay coefficient of variance $(\mathrm{CV})<10 \%$. Although cross-reactivity of the assay with hTNF is $<1 \%$, the exogenous dose of rhTNF in Exp. 2 precluded accurate measurement of endogenous TNF. Concentration of SAA was determined using a multispecies SAA solid phase ELISA kit (Invitrogen Corporation, Carslbad, CA) with assay sensitivity of $9.4 \mu \mathrm{g} / \mathrm{ml}$ and intra-assay $\mathrm{CV}$ of $7.5 \%$. A sheep ELISA kit (Aviva Systems Biology, San Diego, CA) with sensitivity of $5.05 \mathrm{ng} / \mathrm{ml}$ and an intra-assay $\mathrm{CV}$ of $4.1 \%$ was used to measure concentrations of $\mathrm{Hp}$. Concentrations of progesterone were assessed in $25 \mu$ jugular plasma collected on days 9 and 25 by a solid phase, competitive immunoassay (Immulite1000 Siemens Medical Solutions USA, Inc. Malvern, PA) with sensitivity of $0.20 \mathrm{ng} / \mathrm{mL}$ and intra-assay CV of $10.2 \%$ and inter-assay CV of $1.1 \%$.

\subsection{White Blood Cell Counts}

Total WBC counts were obtained (Beckman Coulter, Pasadena, CA) immediate- 
ly after collection. A WBC differential was determined by thinly spreading $5 \mu \mathrm{L}$ of whole blood over a glass slide, air drying, and staining with Giemsa stain (Sigma-Aldrich, Inc., St. Louis, MO). One hundred cells were counted and classified among monocyte, lymphocyte, eosinophil, neutrophil or basophil cell types [16].

\subsection{Statistical Analysis}

For each experiment, data for rectal temperature and concentrations of TNF, SAA, and Hp, and, for experiment 2, concentrations of white blood cells (total, lymphocytes, neutrophils, and monocytes) were analyzed by repeated measures using the ANOVA mixed procedure of SAS followed by the Tukey-Kramer adjustments for multiple comparisons (v.9.3 SAS Inst., Cary, NC). Main effects were treatment, hour, and their interaction. In experiment 2, mucosal responses, lethargy, pregnancy status, and lambing were analyzed as categorical data using a contingency table with Fisher's exact test. Concentrations of progesterone were analyzed for days 9 and 25 by ANOVA for effects of treatment. $\mathrm{P}<0.05$ was considered significant.

\section{Results}

\subsection{Clinical Signs}

Treatment with LPS increased rectal temperature (Exp. 1, mean increase $1.7^{\circ} \mathrm{C}$, Figure 1(a) and Exp. 2, mean increase $2^{\circ} \mathrm{C}$, Figure 1(b)). Pre-treatment with flunixin meglumine (Exp. 1) or dexamethasone (Exp. 2) attenuated the LPS-induced increase in rectal temperature $\left(1.0^{\circ}\right.$ and $0.8^{\circ}$, respectively; Figure $1(\mathrm{a}), \mathrm{P}<$ 0.0001 ), while rectal temperature in control and TNF ewes varied little over time. Treatment with LPS induced clinical signs (Exp. 2) characteristic of immune responses: lethargy in 7 of 9 ewes, and a mucosal response (watery eyes, runny nose, coughing, or vaginal discharge) in 8 of 9 ewes 1 to 4 hours post injection. In contrast to LPS-treated ewes, none of the ewes treated with dexamethasone, TNF, or saline became lethargic; only treatment with TNF induced mucosal responses (5/10 ewes) as seen with LPS.

\subsection{Assays}

In both experiments, LPS induced increases in plasma concentrations of TNF, which peaked at 1.5 and $1 \mathrm{~h}$, respectively. Jugular concentrations of TNF in ewes pre-treated with flunixin meglumine increased in comparable fashion to ewes treated only with LPS increasing from $0.13 \mathrm{ng} / \mathrm{ml}$ to a peak of $1.08 \mathrm{ng} / \mathrm{ml}$ (Figure 2(a)). The response was attenuated $(\mathrm{P}<0.05)$ in LPS and dexamethasone ewes (Figure 2(b)). Concentrations of SAA increased after $3 \mathrm{~h}$ in a similar manner in LPS, LPS and dexamethasone, and TNF ewes with little change in controls (Figure 2(c), P < 0.0001). Treatment with LPS induced a linear increase in concentrations of $\mathrm{Hp}$ between 0 and $12 \mathrm{~h}$, while pre-treatment with dexamethasone attenuated that increase (Figure $2(\mathrm{~d}), \mathrm{P}<0.0001)$. Control ewes showed 


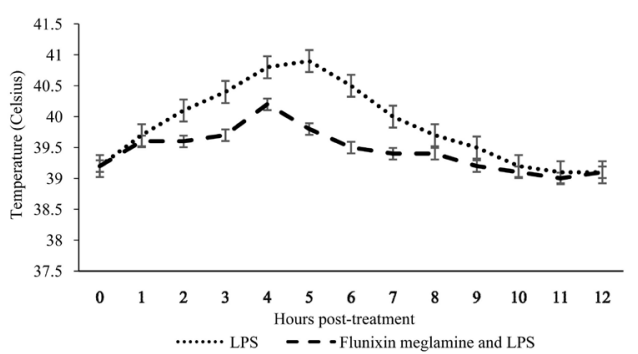

(a)

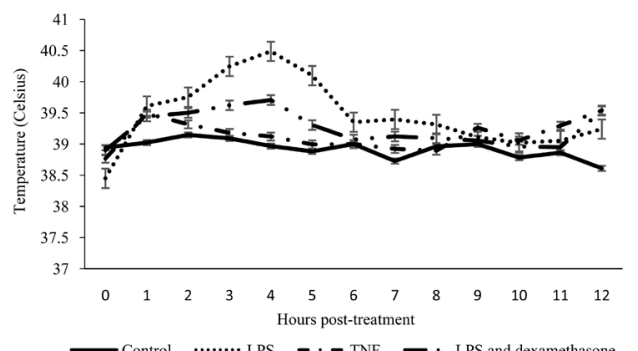

(b)

Figure 1. Rectal temperatures. Panel A-Rectal temperatures in ewes ( $\mathrm{n}=9$ /group) after treatment with either LPS or flunixin meglumine + LPS $(\mathrm{P}<0.05)$. Panel B-Rectal temperatures in ewes after treatment with either saline (Control $n=9)$, LPS $(n=9)$, TNF $(n=$ $10)$, or LPS + dexamethasone $(n=10)$. Effect of treatment $(P=0.001)$, hour $(P<0.0001)$, and treatment $\times$ hour $(\mathrm{P}<0.0001)$.

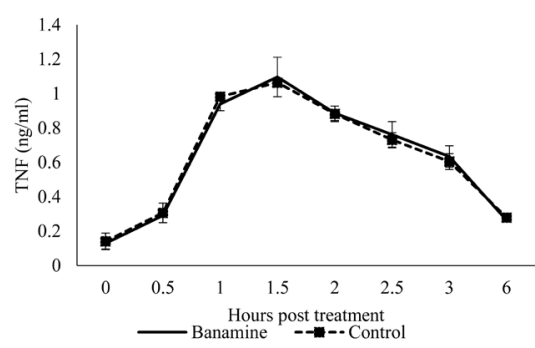

(a)

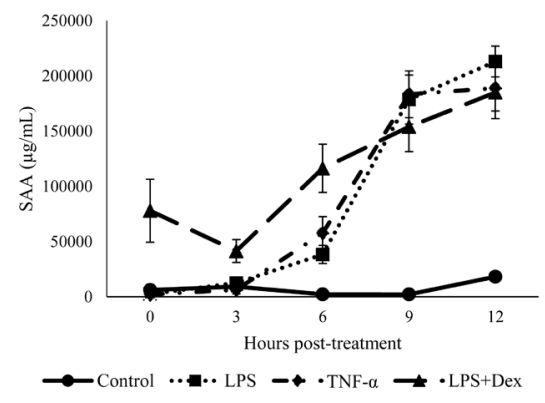

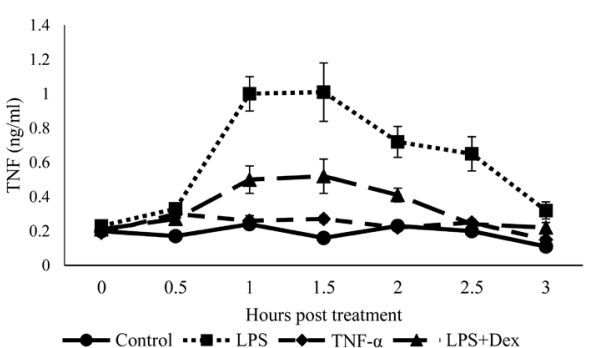

(b)

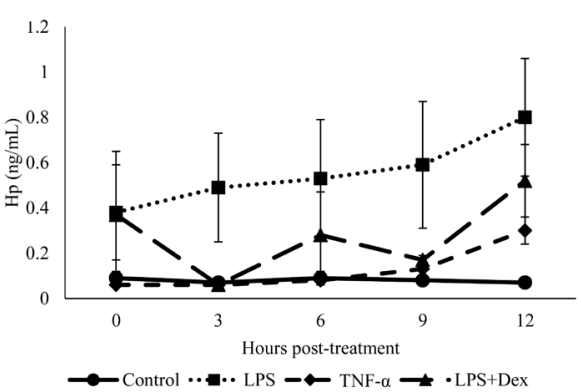

(d)

Figure 2. Jugular concentrations of TNF and acute phase proteins. (a) Concentrations of tumor necrosis factor alpha (TNF) in flunixin meglumine vs control; (b) Concentrations of TNF in ewes after treatment with either saline (Control $n=9)$, LPS $(n=9)$, TNF $(n=$ $10)$, or LPS + dexamethasone $(n=10)$ : treatment $(P<0.0001)$, hour $(P<0.0001)$, and treatment by hour $(\mathrm{P}<0.0001)$; (c) Concentrations of serum amyloid A (SAA): treatment $(\mathrm{P}<0.0001)$, hour $(\mathrm{P}<0.0001)$, and treatment $\times$ hour $(\mathrm{P}<0.0001)$. Panel $\mathrm{D}$-Concentrations of haptoglobin $(\mathrm{Hp})$ : treatment $(\mathrm{P}<0.005)$, hour $(\mathrm{P}<0.0001)$, treatment $\times$ hour $(\mathrm{P}<$ $0.0001)$. 
little change in concentrations of Hp over time, while treatment with TNF increased concentrations only at $12 \mathrm{~h}$.

\subsection{White Blood Cells}

In Exp. 2, total WBC (Figure 3(a)) differed by treatment $(\mathrm{P}<0.0001)$, hour ( $\mathrm{p}<$ $0.0001)$, and treatment by hour $(\mathrm{P}<0.0001)$. Total WBCs decreased the first hour after treatment with LPS, remained lower than control through $6 \mathrm{~h}$, but exceeded the control values after $9 \mathrm{~h}$. The pattern was comparable for the neutrophils with effects of treatment $(\mathrm{P}<0.05)$, hour $(\mathrm{P}<0.0001)$, and treatment by hour $(P<0.005$, Figure $3(\mathrm{~d}))$. For both WBCs and neutrophils, LPS- and dexamethasone-treated ewes showed decreased counts at the first hour, then counts increased and exceeded all treatment groups after $6 \mathrm{~h}$, while counts in control and TNF-treated ewes remained similar. Monocyte concentrations differed by treatment (Control 1.6, LPS 1.3, TNF 2.6 and LPS + dexamethasone $2.9 \times 10^{6}$ cells $\left./ \mathrm{ml}, \mathrm{P}=0.01\right)$ and hour $(\mathrm{P}<0.0001)$ increasing after $6 \mathrm{~h}$ (Figure $3(\mathrm{~b})$ ). Lymphocyte concentrations (Figure $3(\mathrm{c})$ ) differed by treatment (Control 20.8, LPS 15.2, TNF 12.3 and LPS + dexamethasone $9.9 \times 10^{6}$ cells $/ \mathrm{ml}, \mathrm{P}<$ $0.0001)$ and hour $(\mathrm{P}<0.0001)$ with a tendency for a treatment by hour effect $(\mathrm{P}$ $=0.09)$. Lymphocyte concentrations decreased until $5 \mathrm{~h}$ followed by a rebound in all groups with control having twice the number of cells $(3,000,000$ cells $/ \mathrm{ml})$ as LPS, TNF, and LPS + dexamethasone.

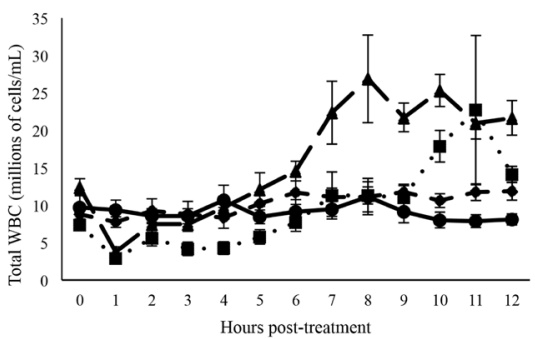

(a)

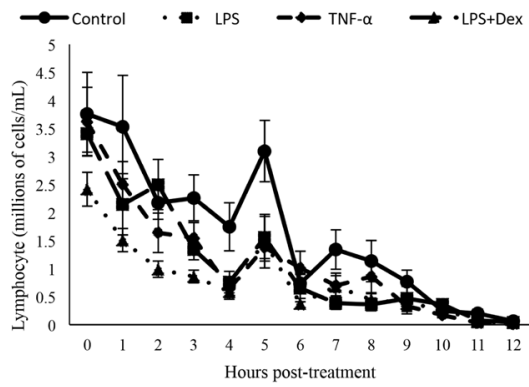

(c)

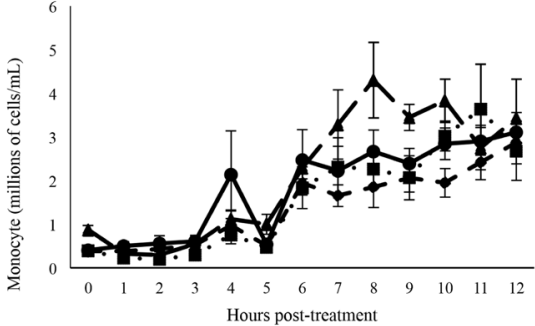

(b)

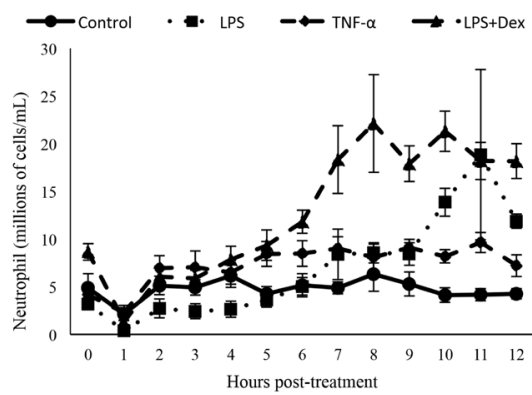

Figure 3. Jugular white blood cell counts. (a) Total white blood cell (WBC) concentration in jugular blood in ewes after treatment with either saline (Control, $n=9)$, LPS $(n=9)$, TNF $(\mathrm{n}=10)$, or LPS + dexamethasone $(\mathrm{n}=10)$ : treatment $(\mathrm{P}<0.0001)$, hour $(\mathrm{P}<$ $0.0001)$, treatment $\times$ hour $(\mathrm{P}<0.0001)$; (b) Concentrations of monocytes: treatment $(\mathrm{P}=$ $0.01)$, hour $(\mathrm{P}<0.0001)$, treatment $\times$ hour $(\mathrm{P}>0.15)$; (c) Concentrations of lymphocytes: treatment $(\mathrm{P}<0.0001)$, hour $(\mathrm{P}<0.0001)$, treatment $\times$ hour $(\mathrm{P}=0.088)$; $(\mathrm{d})$ Concentrations of neutrophils: treatment $(\mathrm{P}<0.05)$, hour $(\mathrm{P}<0.0001)$, treatment $\times$ hour $(\mathrm{P}<0.005)$. 


\subsection{Pregnancy}

In Exp. 1, 3 of the 9 LPS treated ewes and 6 of 9 ewes treated with flunixin meglumine and LPS were pregnant $(\mathrm{P}=0.16)$. In Exp. 2, pregnancy rates on $\mathrm{d} 25$ in control (7/9) and TNF treated (8/10) ewes tended to be greater than LPS-treated (4/9) and LPS and dexamethasone-treated (5/10) ewes. Similar proportions of the pregnant control (7/7), TNF (7/8), LPS (3/4) and LPS and dexamethasone ewes (4/5) lambed with comparable litter sizes. Overall, lambing rates were affected more by embryonic ( 14 ewes) than fetal ( 3 ewes) losses. Although concentrations of progesterone were similar among groups on day $9(2.12 \pm 0.14 \mathrm{ng} / \mathrm{ml})$, concentrations on day 25 in the control $(2.98 \mathrm{ng} / \mathrm{ml})$ and TNF-treated $(3.06 \mathrm{ng} / \mathrm{ml})$ ewes were greater than those for LPS $(1.48 \mathrm{ng} / \mathrm{ml})$ and LPS and dexamethasone-treated $(2.13 \mathrm{ng} / \mathrm{ml})$ ewes (SE $0.25, \mathrm{P}=0.07)$, which agrees with the apparently higher pregnancy rates in control (7/9) and TNF-treated (7/10) ewes than LPS (3/9) and LPS + dexamethasone treated $(4 / 10)$ ewes $(\mathrm{P}=0.14)$.

\section{Discussion}

In previous studies [7] [8] [9], mated ewes inoculated with peptidoglycan-polysaccharide or killed Streptococcus pyogenes, a gram-positive bacterium, showed typical physical and immunological changes including transient increases in serum concentrations of TNF, cortisol, HP and SAA after bacterial challenge and increased serum concentrations of PGFM and reduced serum concentrations of progesterone, which were associated with decreased early embryonic survival. Numerous studies [17] have shown increased embryonic loss after treatment with Gram-negative bacteria or its antigen, LPS. Although peptidoglycan-polysaccharide binds to TLR2 and LPS binds to TLR4, both activate the NF- $\kappa$ B cytokine signaling pathway.

Ewes treated with LPS showed the expected increase in rectal temperature, typical mucosal and behavioral responses, changes in immunological cell profile (leukopenia, etc.), transient increases in concentrations of TNF and cortisol, and resolution of the immunological response within 6 - $9 \mathrm{~h}$ after the single challenge injection. Treatment with flunixin meglumine blunted the LPS-induced fever but had no effect on serum concentrations of $\operatorname{TNF} \alpha$, which increased in a pattern comparable to that in ewes treated with LPS treatment alone, and tended to increase pregnancy rate indicative of a role of prostaglandin synthesis in pregnancy losses due to LPS. Treatment of cows with flunixin meglumine 14 days after insemination improved pregnancy rates compared to non-treated cows [18]. Because pregnancy rate was similar in TNF and control ewes but higher than in ewes treated with LPS or LPS and flunixin meglumine, the increased mucosal responses after TNF injection alone did not account for the observed changes in pregnancy rate in the LPS-challenged ewes. In fact, 6/13 ewes that displayed a mucosal response lambed compared to $15 / 25$ of those that did not show a mucosal response. Treatment with TNF did not alter rectal temperature nor pregnancy rate, while LPS did; hence, change in rectal temperature 
could be part of the mechanism for embryonic loss. Indeed, only 13/28 of the ewes showing increased rectal temperature lambed compared to $8 / 10$ ewes that did not show increased rectal temperature.

Traditionally, administration of glucocorticoids has been associated with suppression of immune responses, particularly to LPS [19]. Dexamethasone reduced endotoxin levels, inflammatory mediators and down-regulated expression of NF- $\kappa$ B in ileal mucosa [20]. The dosage of dexamethasone used in Exp. 2 affected fetal hypothalamic maturation when administered to ewes on d $41-42$ of gestation [21]. Treatment of ewes with dexamethasone dampened both the LPS-induced increase in rectal temperature and incidences of mucosal responses and of lethargy; thus, the dosage of dexamethasone provided the expected anti-inflammatory response. Glucocorticoids down-regulate pro-inflammatory genes such as those encoding for COX-2 [22], which could explain why dexamethasone-treated ewes displayed less fever than ewes treated with just LPS. Ewes treated with dexamethasone had the second highest TNF concentration at $0 \mathrm{~h}$ of the treatment groups. Enhanced TNF responses to LPS were observed in mice exposed to dexamethasone 24 - $48 \mathrm{~h}$ before LPS [23], and pro-inflammatory mediators were up-regulated if glucocorticoids were administered prior (2 and $24 \mathrm{~h}$ ) to a peripheral LPS challenge [24].

A decline in total WBCs, monocytes, neutrophils, $\mathrm{Hp}$, and SAA was seen until $3 \mathrm{~h}$ in dexamethasone-treated ewes irrespective of elevated starting counts of immune cells prior to LPS challenge, which demonstrates a priming effect of administering dexamethasone prior to the LPS challenge. Subsequently, neutrophils, monocytes, $\mathrm{Hp}$, and SAA showed an increase after $3 \mathrm{~h}$ that persisted until $12 \mathrm{~h}$, possibly due to the short half-life (1.8 to $3.5 \mathrm{~h}$ ) of dexamethasone. Prior to injection of LPS, a high percentage of lymphocytes was seen in all groups with a shift to predominately monocytes and neutrophils occurring post-LPS challenge, which is indicative of an innate immune response initiated by the injection of LPS or TNF. Stress of handling the animals [25] could have caused increased production of WBCs and then induction of a strong innate immune response or perhaps handling stress, as observed in restrained rats [26], could have caused the decrease in the blood lymphocyte population. Further, increases in plasma cortisol concentrations were associated with decreases in circulating concentrations of lymphocytes between 0 and $8 \mathrm{~h}$ post injection of LPS [27]. At $12 \mathrm{~h}$, neutrophils were the highest percentage of cells in all groups, which was expected because they are the most abundant cellular component of host immunity and primary mediators of the innate immune response. Lymphocyte concentrations decreased throughout the experiment and rebounded by $24 \mathrm{~h}$.

\section{Conclusion}

In summary, challenge with LPS resulted in an early innate immune response, which was followed by an apparently decreased pregnancy rate. Dexamethasone given prior to LPS elicited a "priming" effect on WBCs and decreased clinical 
signs and some innate immune responses but did not inhibit the LPS-induced pregnancy loss. The cytokine TNF alone may not be responsible for early embryonic death, but in the context of a full innate immune response, such as that induced by LPS, TNF along with other pro-inflammatory cytokines may collectively contribute to early embryonic death.

\section{Acknowledgements}

This investigation was supported by the USDA National Institute of Food and Agriculture [Animal Health WVA00904 and Project 476 Hatch NE-1227] and the West Virginia Agricultural and Forestry Experiment Station.

\section{Conflicts of Interest}

The authors declare no conflicts of interest regarding the publication of this paper.

\section{References}

[1] Barker, A.R., Schrick, F.N., Lewis, M.J., Dowlen, H.H. and Oliver, S.P. (1998) Influence of Clinical Mastitis during Early Lactation on Reproductive Performance of Jersey Cows. Journal of Dairy Science, 81, 1285-1290. https://doi.org/10.3168/jds.S0022-0302(98)75690-5

[2] Soto, P., Natzke, R.P. and Hansen, P.J. (2003) Action of Tumor Necrosis Factor- $\alpha$ on Oocyte Maturation and Embryonic Development in Cattle. American Journal of Reproductive Immunology, 50, 380-388. https://doi.org/10.1034/j.1600-0897.2003.00101.x

[3] Hansen, P.J., Soto, P. and Natzke, R.P. (2004) Mastitis and Fertility in Cattle-Possible Involvement of Inflammation or Immune Activation in Embryonic Mortality. American Journal of Reproductive Immunology, 51, 294-304. https://doi.org/10.1111/j.1600-0897.2004.00160.x

[4] Cullor, J.S. (1990) Mastitis and Its Influence upon Reproductive Performance in Dairy Cattle. Proceedings International Symposium on Bovine Mastitis, Indianapolis, 13-16 September 1990, 176.

[5] Dubin, N.H., Bornstein, D.R. and Gong Y. (1995) Use of Endotoxin as a Positive (Toxic) Control in the Mouse Embryo Assay. Journal of Assisted Reproductive Genetics, 12,147-152. https://doi.org/10.1007/BF02211385

[6] Randall, G.W., O’Connor, E.F. and Gantt, P.A. (1991) Synergy between Tumor Necrosis Factor and Endotoxin Decreases Early Development in Vitro. Journal of in Vitro Fertility and Embryo Transfer, 8, 304-307. https://doi.org/10.1007/BF01133018

[7] Stewart, A.B., Inskeep, E.K., Townsend, E.C. and Dailey, R.A. (2003) Effects of Gram-Positive Bacterial Pathogens in Ewes: Peptidoglycan as a Potential Mediator of Interruption of Early Pregnancy. Reproduction, 125, 295-299. https://doi.org/10.1530/rep.0.1250295

[8] Holásková, I., Lewis, G.S., Elliot, M., Blemings, K.P. and Dailey, R.A. (2004) Effect of Peptidoglycan-Polysaccharide Complex on Reproductive Efficiency in Sheep. American Journal of Reproductive Immunology, 52, 197-203. https://doi.org/10.1111/j.1600-0897.2004.00206.x

[9] Dow, T.L., Rogers-Nieman, G., Holásková, I., Elsasser, T.H. and Dailey, R.A. (2010) 
Tumor Necrosis Factor- $\alpha$ and Acute-Phase Proteins in Early Pregnant Ewes after Challenge with Peptidoglycan-Polysaccharide. Domestic Animal Endocrinology, 39, 147-154. https://doi.org/10.1016/j.domaniend.2010.04.001

[10] Davidson, J.A., Tiemann, U., Betts, J.G. and Hansen, P.J. (1995) DNA Synthesis and Prostaglandin Secretion by Bovine Endometrial Cells as Regulated by Interleukin-1. Reproduction, Fertility and Development, 7, 1037-1043. https://doi.org/10.1071/RD9951037

[11] Inskeep, K., Lewis, P., Stilley, N., Mulledy, R. and Dinsmore, H. (1983) Synchronization of Estrus as a Management Tool in the Ewe Flock. Agricultural and Forestry Experiment Station, West Virginia University, Morgantown.

[12] Dixon, A.B., Knights, M., Pate, J.L., Lewis, P.E. and Inskeep, E.K. (2006) Reproductive Performance of Ewes after 5-Day Treatment with Intravaginal Inserts Containing Progesterone in Combination with Injection of Prostaglandin $\mathrm{F}_{2} \alpha$. Reproduction in Domestic Animals, 41, 142-148. https://doi.org/10.1111/j.1439-0531.2006.00656.x

[13] Elsasser, T.H., Kahl, S., MacLeod, C., Nicholson, B., Sartin, J.L. and Li, C. (2004) Mechanisms Underlying Growth Hormone Effects in Augmenting Nitric Oxide Production and Protein Tyrosine Nitration during Endotoxin Challenge. Endocrinology, 145, 3413-3423. https://doi.org/10.1210/en.2004-0063

[14] Hadfield, J.M., Bowdridge, E.C., Holásková, I., Elsasser, T.H. and Dailey, R.A. (2018) Breed-Specific Differences in the Immune Response to Lipopolysaccharide in Ewes. Journal of Animal Science, 96, 4220-4228. https://doi.org/10.1093/jas/sky288

[15] Kenison, D.C., Elsasser, T.H. and Fayer, R. (1990) Radioimmunoassay for Tumor Necrosis Factor: Concentrations and Circulating Molecular Forms in Bovine Plasma. Journal of Immunoassay, 11, 177-198. https://doi.org/10.1080/01971529008053268

[16] Harvey, J.W. (2012) Veterinary Hematology: A Diagnostic Guide and Color Atlas. Saunders, Philadelphia.

[17] Gendron, R.L., Nestel, F.P., Lapp, W.S. and Baines, M.G. (1990) Lipopolysaccharide-Induced Fetal Resorption in Mice Is Associated with the Intrauterine Production of Tumour Necrosis Factor-Alpha. Journal of Reproduction and Fertility, 90, 395-402. https://doi.org/10.1530/jrf.0.0900395

[18] Merrill, M.L., Ansotegui, R.P., Burns, P.D., MacNeil, M.D. and Geary, T.W. (2007) Effects of Flunixin Meglumine and Transportation on Establishment of Pregnancy in Beef Cows. Journal of Animal Science, 85, 1547-1554. https://doi.org/10.2527/jas.2006-587

[19] Coutinho, A.E. and Chapman, K.E. (2011) The Anti-Inflammatory and Immunosuppressive Effects of Glucocorticoids, Recent Developments and Mechanistic Insights. Molecular and Cellular Endocrinology, 335, 2-13. https://doi.org/10.1016/j.mce.2010.04.005

[20] Zhang, X., Chen, L., Luo, L., Tian, H., Feng, G., Cai, Y., Xu, R., Wang, K. and Wang, Z. (2008) Study of the Protective Effects of Dexamethasone on Ileum Mucosa Injury in Rats with Severe Acute Pancreatitis. Pancreas, 37, 74-82. https://doi.org/10.1097/MPA.0b013e3181800d11

[21] Li, S., Nitsos, I., Polglase, G.R., Braun, T., Moss, T.J., Newnham, J.P. and Challis, J.R. (2012) The Effects of Dexamethasone Treatment in Early Gestation on Hypothalamic-Pituitary-Adrenal Responses and Gene Expression at 7 Months of Postnatal Age in Sheep. Animal Reproductive Science, 19, 260-270. 
https://doi.org/10.1177/1933719111418374

[22] Barrios-Rodiles, M., Tiraloche, G. and Chadee, K. (1999) Lipopolysaccharide Modulates Cyclooxygenase-2 Transcriptionally and Posttranscriptionally in Human Macrophages Independently from Endogenous IL- $1 \beta$ and TNF- $\alpha$. Journal of Immunology, 163, 963-969.

[23] Fantuzzi, G., Demitri, M.T. and Ghezzi, P. (1994) Differential Effect of Glucocorticoids on Tumor Necrosis Factor Production in Mice: Up-Regulation by Early Pretreatment with Dexamethasone. Clinical and Experimental Immunology, 96, 166-169. https://doi.org/10.1111/j.1365-2249.1994.tb06247.x

[24] Frank, M.G., Miguel, Z.D., Watkins, L.R. and Maier, S.F. (2010) Prior Exposure to Glucocorticoids Sensitizes the Neuroinflammatory and Peripheral Inflammatory Responses to E. coli Lipopolysaccharide. Brain, Behavior, and Immunity, 24, 19-30. https://doi.org/10.1016/j.bbi.2009.07.008

[25] Murata, H., Takahashi, H. and Matsumoto, H. (1987) The Effects of Road Transportation on Peripheral Blood Lymphocyte Subpopulations, Lymphocyte Blastogenesis and Neutrophil Function in Calves. British Veterinary Journal, 143, 166-174. https://doi.org/10.1016/0007-1935(87)90008-X

[26] Dhabhar, F.S., Miller, A.H., McEwen, B.S. and Spencer, R.L. (1995) Effects of Stress on Immune Cell Distribution; Dynamics and Hormonal Mechanisms. Journal of Immunology, 154, 5511-5527.

[27] Hopster, H., van der Werf, J.T.N. and Blokhuis, H.J. (1998) Stress Enhanced Reduction in Peripheral Blood Lymphocyte Numbers in Dairy Cows during Endotoxin-Induced Mastitis. Veterinary Immunology Immunopathology, 66, 83-97. https://doi.org/10.1016/S0165-2427(98)00189-5 